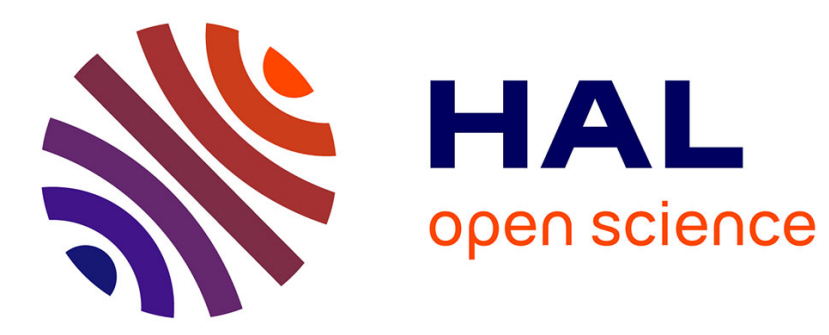

\title{
Rib Cage Measurement Reproducibility Using Biplanar Stereoradiographic 3D Reconstructions in Adolescent Idiopathic Scoliosis
}

Raphaël Pietton, Houssam Bouloussa, Claudio Vergari, Wafa Skalli, Raphaël Vialle

\section{To cite this version:}

Raphaël Pietton, Houssam Bouloussa, Claudio Vergari, Wafa Skalli, Raphaël Vialle. Rib Cage Measurement Reproducibility Using Biplanar Stereoradiographic 3D Reconstructions in Adolescent Idiopathic Scoliosis. Journal of Pediatric Orthopedics, In press, 10.1097/BPO.0000000000001095 . hal01797585

\section{HAL Id: hal-01797585 \\ https://hal.science/hal-01797585}

Submitted on 22 May 2018

HAL is a multi-disciplinary open access archive for the deposit and dissemination of scientific research documents, whether they are published or not. The documents may come from teaching and research institutions in France or abroad, or from public or private research centers.
L'archive ouverte pluridisciplinaire HAL, est destinée au dépôt et à la diffusion de documents scientifiques de niveau recherche, publiés ou non, émanant des établissements d'enseignement et de recherche français ou étrangers, des laboratoires publics ou privés. 


\title{
RIB CAGE MEASUREMENT REPRODUCIBILITY USING BIPLANAR
}

\section{STEREORADIOGRAPHIC 3D RECONSTRUCTIONS IN ADOLESCENT IDIOPATHIC SCOLIOSIS}

\author{
Raphael Pietton MD ${ }^{1,2}$, Houssam Bouloussa MD ${ }^{1}$, Claudio Vergari PhD ${ }^{2,3}$, \\ Wafa Skalli $\mathrm{PhD}^{2}$, Raphaël Vialle MD PhD ${ }^{1}$.
}

\section{Abstract}

Background: A reproducibility study of preoperative rib cage 3D measurements was conducted for patients with Adolescent Idiopathic Scoliosis (AIS). No prior reliability study has been performed for preoperative 3D reconstructions of the rib cage by using stereoradiography in patients with preoperative AIS. Our Objective was to assess the reliability of rib cage 3D reconstructions using biplanar stereoradiography in patients with AIS before surgery.

Materials: This series includes 21 patients with Lenke 1 or 2 scoliosis $\left(74^{\circ}+-20\right)$. All patients underwent low-dose standing biplanar radiographs. Two operators performed reconstructions twice each. Intraoperator repeatability, interoperator reproducibility and Intraclass coefficients (ICC) were calculated and compared between groups.

Results: The average rib cage volume was $4.71 \mathrm{~L}$ (SD $\pm 0.75 \mathrm{~L}$ ). $2 \mathrm{SD}$ was $0.19 \mathrm{~L}$ with a coefficient of variation of $4.1 \%$; ICC was 0.968 . The thoracic index was 0.6 (SD \pm 0.1 ). $2 \mathrm{SD}$ was 0.03 with a coefficient of variation of $4.7 \%$ and a ICC of 0.820. As for the Spinal Penetration Index (6.4\%; SD \pm 2.4$)$, 2SD was $0.9 \%$ with a coefficient of variation of $14.3 \%$ and a ICC of 0.901 . The 3D rib hump 2SD (average $27^{\circ} \pm 8^{\circ}$ ) was $1.4^{\circ}$. The coefficient of variation and ICC were respectively $5.1 \%$ and 0.991 .

Conclusion: 3D reconstruction of the rib cage using biplanar stereoradiography is a reliable method to estimate preoperative thoracic parameters in patients with AIS.

Level of evidence: Diagnostic study- Level IV

1: Dept. of Pediatric orthopedic, Armand Trousseau Hospital, Paris 6 University, France.

2 Arts et Métiers ParisTech, LBM/Institut de Biomécanique Humaine Georges Charpak, 151 bd de l'Hôpital, 75013, Paris, France. 


\section{INTRODUCTION}

Following the development of biplanar stereoradiography, the 3D radiographic assessment of Adolescent Idiopathic Scoliosis has become much more accessible, making reconstructions easier and faster. Biplanar X-rays allow 3D reconstructions of both vertebrae and rib cage. The reconstruction method for vertebrae is well-known today and its reliability has already been assessed:[1] Ilharreborde et al ${ }^{1}$ have shown excellent intraoperator repeatability and interoperator reproducibility for preoperative and postoperative spinal reconstructions in AIS patients. This study confirmed the reliability of 3D parameter measurements in patients with severe scoliosis. Accuracy and reproducibility of 3D rib cage reconstruction have been assessed for moderate scoliosis with a mean major curve of $37^{\circ}$ [2] but not for severe scoliosis. Rib cage deformity[3] due to severe scoliosis can lead to restrictive lung disease[4], [5], and pulmonary function is one of the major issues in the management of AIS. CT-scan or MRI are usually performed to assess a three-dimensional deformity and are the gold standard to assess stereoradiography accuracy. Both techniques have the disadvantage of being performed supine, which modifies the frontal and transverse spinal curvatures[6], [7] and require the digital generation of stereoradiography. CT-scan and repeated traditional X-rays generate a significant radiation exposure[8], [9]. Biplanar radiographs combined with $3 \mathrm{D}$ reconstructions of the spine and rib cage could be a more effective method for the evaluation of the relationships between thoracic parameters and pulmonary function in AIS. However, because of the curve severity, the visibility of the anatomical landmarks used for reconstruction could be altered with an impact on the reliability of the clinical parameters. The purpose of this study was to assess the reliability of preoperative $3 \mathrm{D}$ rib cage reconstructions and associated clinical parameters using low-dose biplanar stereoradiography in patients with severe AIS.

\section{MATERIALS AND METHODS}

\section{Patients}

Twenty-one patients with severe Lenke 1 or 2 AIS (main thoracic curve $>50^{\circ}$ ) were prospectively included after institutional board approval. The cohort was composed of a consecutive series of patients followed by a single senior surgeon in our institution. Data collection was approved by the institution's ethical committee.

\section{Biplanar stereoradiography system}

Low-dose biplanar X-rays were acquired routinely in our institution. Patients were in erect free standing position, hands on clavicles to avoid any superimposition with the spine. Exposure parameters were $83 \mathrm{kV}$ and $200 \mathrm{~mA}$ for the anteroposterior (AP) Xray; $102 \mathrm{kV}$ and $200 \mathrm{~mA}$ for the lateral view. All images included at least both the last cervical vertebra (C7) and the pelvis. Dose area product averaged $411 \mathrm{mGy} \cdot \mathrm{cm}^{2}$ for the AP X-ray and 656 $\mathrm{mGy} \cdot \mathrm{cm}^{2}$ for the lateral X-ray. Acquisitions were performed using a slot-scanning radiological device (EOS 


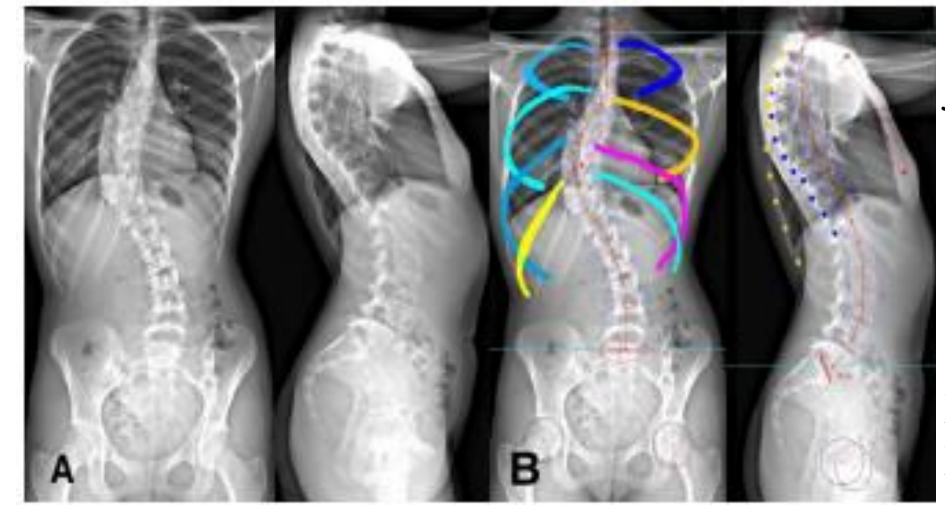

Figure 1: A/ AP and lateral initial biplanar X-rays B/ first step of rib cage reconstruction by contouring.

system, EOS Imaging, Paris, France) consisting of two X-ray sources, allowing simultaneous acquisition of two images. The sources are coupled with linear detectors that are based on micromesh gaseous structure technology[10], [11]. The two sourcedetector pairs are positioned orthogonally so that the patient's anteroposterior and lateral images are generated simultaneously line by line, while the whole system is vertically translated. Scan time lasts from 8 to 15 seconds for a spinal examination, depending on patient's height. Patients held their breath during the 6-10 seconds EOS acquisition.

\section{Reconstruction Technique}

The 3D reconstruction of the spine and rib cage from biplanar X-rays using previously validated parametric models[2], [12]. For the reconstruction of the rib cage, a first estimation was made by contouring the ribs and positioning anatomical landmarks such as the sternum and the most posterior points of the ribs on lateral X-rays (Figure 1). This first estimation of the rib cage morphology is also based on a preliminary $3 \mathrm{D}$ reconstruction of the spine in order to automatically define the position of the costo-vertebral joints, and thus the starting point of the ribs midlines. This first estimation was then superimposed on the AP and lateral images, and the operator manually fine-tuned the model though control points placed on the ribs until each rib perfectly fit the X-ray image (Figure 2). This process takes 15 minutes approximatively depending on the major curve severity.

\section{Measurement methods:}

Two operators (medical doctors) completed individual training courses on the $3 \mathrm{D}$ reconstruction of healthy and mild scoliosis rib cage, and they validated their acquired skill by comparing their intra-operator reproducibility with published values. These two operators performed 3D reconstructions of the rib cage twice for each patient (total 42 reconstructions per operator). The operators performed the reconstruction starting from the same spinal 3D reconstruction; this was done to estimate the reliability of the rib cage reconstruction independently of the spine.

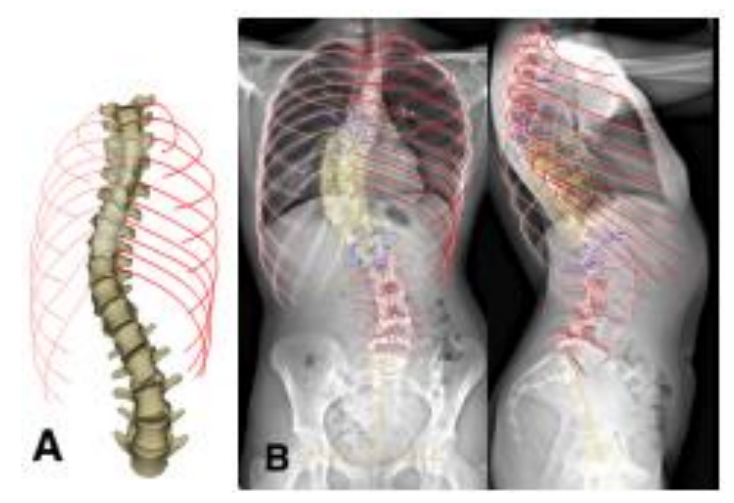

Figure 2: A/ final 3D reconstructions $\mathrm{B} / \mathrm{AP}$ and lateral view showing perfect fit with the biplanar Xray 
The following parameters were calculated for each patient: rib cage volume $\left(\mathrm{cm}^{3}\right)$, thoracic index $(\%)$, maximum anteroposterior diameter $(\mathrm{mm})$, maximum width $(\mathrm{mm})$, spinal penetration index (\%), maximal rib hump 2D (in the horizontal plane) and $3 \mathrm{D}\left({ }^{\circ}\right)$.

Rib cage volume was obtained integrating surfaces extracted from rib reconstructions. The spinal penetration index corresponded to the percentage of rib cage volume penetrated by spinal volume between the third and tenth rib pairs. The thoracic index was calculated as the ratio of the anteroposterior diameter of the thorax and its transverse diameter. Spinal and pelvic parameters were also calculated: main thoracic curve, T1-T12 kyphosis, T4-T12 kyphosis, torsion index, apical vertebral rotation and the pelvic parameters (pelvic tilt, pelvic incidence, sacral slope).

\section{Statistical analysis}

The statistical analysis was made by an independent statistician who was blinded from patients and their clinical status. Reliability of the rib cage reconstruction was quantified by estimating the intra-operator repeatability and inter-operator reproducibility of each clinical parameter. The ISO 5725 international standard was used to calculate repeatability and reproducibility in terms of standard deviation (standard deviation of reproducibility, SDr). Values were reported as twice the SD (2SD) to represent the 95\% confidence interval, consistently with previous literature [2] .

Intraclass correlation coefficient (ICC) was also calculated: ICCs greater than 0.91, between 0.71 and 0.91, between 0.51 and 0.70 , or less than 0.51 were considered to represent very good agreement, good agreement, moderate agreement, or poor agreement, respectively.

\section{RESULTS}

\section{Spinal and pelvic parameters}

The average major curve of the 21 included patients was $74^{\circ} \pm 20^{\circ}$ (range $50-131^{\circ}$ ), confirming the severe stage of the idiopathic scoliosis in our series. The anatomical landmarks were clearly distinguishable by varying the digital image luminosity and contrast to optimally reveal the vertebrae and pelvis. In particular, the ribs and sternum were visible in all cases. Consequently, the 6 thoracic parameters were measurable in all 21 patients. The mean values of the spinal and thoracic parameters of the series are summarized in Table 1 and 2.

\begin{tabular}{|l|c|c|}
\hline \multicolumn{2}{|c|}{$\begin{array}{c}\text { Table 1.Mean Values of spinal and pelvic } \\
\text { parameters }\end{array}$} \\
\hline & Mean & SD \\
\hline Cobb angle $\left(^{\circ}\right)$ & 74.2 & 20.3 \\
\hline Torsion index $\left(^{\circ}\right)$ & 19.1 & 8.8 \\
\hline T1-T12 kyphosis $\left(^{\circ}\right)$ & 32.3 & 16.2 \\
\hline Lordosis L1-S1 $\left(^{\circ}\right)$ & 58.2 & 14.5 \\
\hline Pelvic tilt $\left(^{\circ}\right)$ & 6.4 & 5.1 \\
\hline Pelvic incidence $\left(^{\circ}\right)$ & 46.7 & 13.4 \\
\hline
\end{tabular}

\section{Reproducibility and repeatability}

The measurement repeatability (intraoperator) and reproducibility (interoperator) have been reported in Table 3 and compared to those obtained 

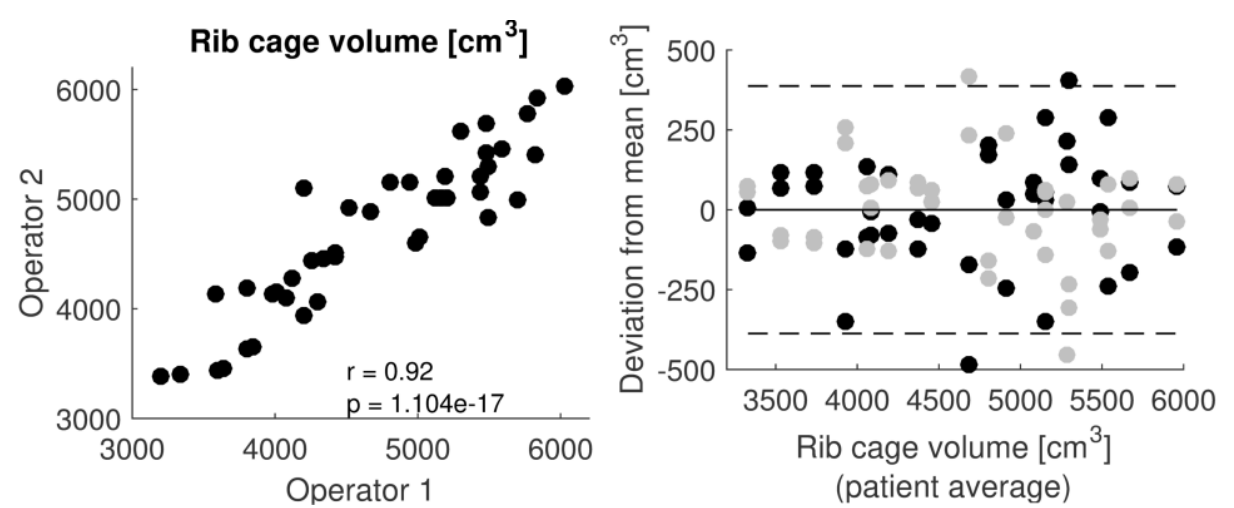

Figure 3: Rib cage volume interoperator reproducibility: correlation between operators and BlandAltmann plot. In the latter plot, black and grey dots represent the two operators while dashed lines represent measurement reproducibility (2SD).

by Aubert et al[2] with mild scoliotic patients. The reproducibility was 387.3 $\mathrm{cm}^{3}$ and $1.9 \%$ for the two most significant thoracic parameters (rib cage volume and spinal penetration index). Intraclass coefficient was higher or equal to 0.8 , showing a good or very good agreement for all parameters.

Bland-Altmann plots for rib cage volume, spinal penetration index and Rib hump results are represented in figure 3, 4 and 5, respectively. They show good agreement between operators and the absence of outlier, as well as robustness of measurements uncertainty with the severity of the scoliosis (i.e., the uncertainty does not increase as the parameter value increases).

Table 2. Mean values of Rib cage parameters

\begin{tabular}{|l|c|c|}
\hline & Mean & SD \\
\hline Rib cage volume $\left(\mathrm{cm}^{3}\right)$ & 4700.7 & 751.7 \\
\hline Spinal penetration index $\left(^{\circ}\right)$ & 6.4 & 2.3 \\
\hline Thoracic Index (\%) & 0.6 & 0.1 \\
\hline 3D Rib Hump $\left(^{\circ}\right)$ & 26.6 & 8.2 \\
\hline 2D Rib Hump $\left(^{\circ}\right)$ & 14.5 & 8.1 \\
\hline Maximum Width (mm) & 228.3 & 144.3 \\
\hline Maximum Thickness (mm) & 144.3 & 21.5 \\
\hline
\end{tabular}

\section{DISCUSSION}

AIS represents the most common threedimensional chest deformity in the general population[13]. Rib cage radiographic assessment was previously performed with chest X-rays allowing only AP and lateral views that were a projection of a three-dimensional deformity in two dimensions. Over the past two decades, three-dimensional imaging (MRI and CT) have growingly been used for that purpose. Recently, a significant relationship has been shown between chest parameters such as the hump or the apical vertebral rotation with clinical parameters[14], [15]. Both examinations have had a restrictive use either because of their irradiation (CTscan) or their complexity, accessibility and cost (MRI). Besides, it has been shown that chest parameters varied between the supine and standing position [7]. Moreover, CT raises an issue for children because of high radiation doses and increased risk of radiation-induced cancer[16]. The studied parameters have a clinical interest in the diagnosis, monitoring and surgical strategy in AIS. Biplanar stereoradiography is a fast and lowdose technology to obtain a three 


\begin{tabular}{|l|c|c|c|c|}
\hline \multicolumn{5}{|c|}{ Table 3. Rib cage measurements reproducibility and repeatability } \\
\hline & $\begin{array}{c}\text { Intraoperator } \\
\text { repeatability } \\
\text { (2SD, coefficient } \\
\text { of variation \%) }\end{array}$ & $\begin{array}{c}\text { Interoperator } \\
\text { reproducibility } \\
2 \text { SD, coefficient of } \\
\text { variation \%) }\end{array}$ & Aubert et al & ICC \\
\hline Rib cage volume $\left(\mathrm{cm}^{3}\right)$ & $233.4(4 \%)$ & $387.3(8 \%)$ & 294 & 0.968 \\
\hline Spinal penetration Index $\left(^{\circ}\right)$ & $1(16 \%)$ & $1.9(28 \%)$ & 1.2 & 0.901 \\
\hline 3D Rib Hump $\left(^{\circ}\right)$ & $2.1(8 \%)$ & $2.1(8 \%)$ & & 0.991 \\
\hline 2D Rib Hump $\left(^{\circ}\right)$ & $2(14 \%)$ & $3.5(24 \%)$ & 5 & 0.973 \\
\hline Maximum Width $(\mathrm{mm})$ & $3(2 \%)$ & $4.4(2 \%)$ & 3.2 & 0.989 \\
\hline Maximum Thickness (mm) & $6.9(4 \%)$ & $14.7(10 \%)$ & 9.3 & 0.800 \\
\hline Thoracic Index $(\%)$ & $0.02(4 \%)$ & $0.06(10 \%)$ & & 0.820 \\
\hline
\end{tabular}

dimensional

model-based reconstructions of the spine and rib cage for patients in erect standing posture[12], [17]-[19].

A semi-automated reconstruction method was used in this study. A few studies[20]-[22] showed the validity of this type of semi-automated reconstruction process compared with CT-scan based reconstructions. This allows a significant time reduction for spinal reconstructions, which is essential for routine clinical use. Sabourin and al [22] used a semiautomatic method as well, but in three steps. Rib trajectories were determined using four landmark points.

This model of the rib cage constituted the prepersonalized rib cage model which was deformed to personalize the model. The main limitation was that each rib had to be individually
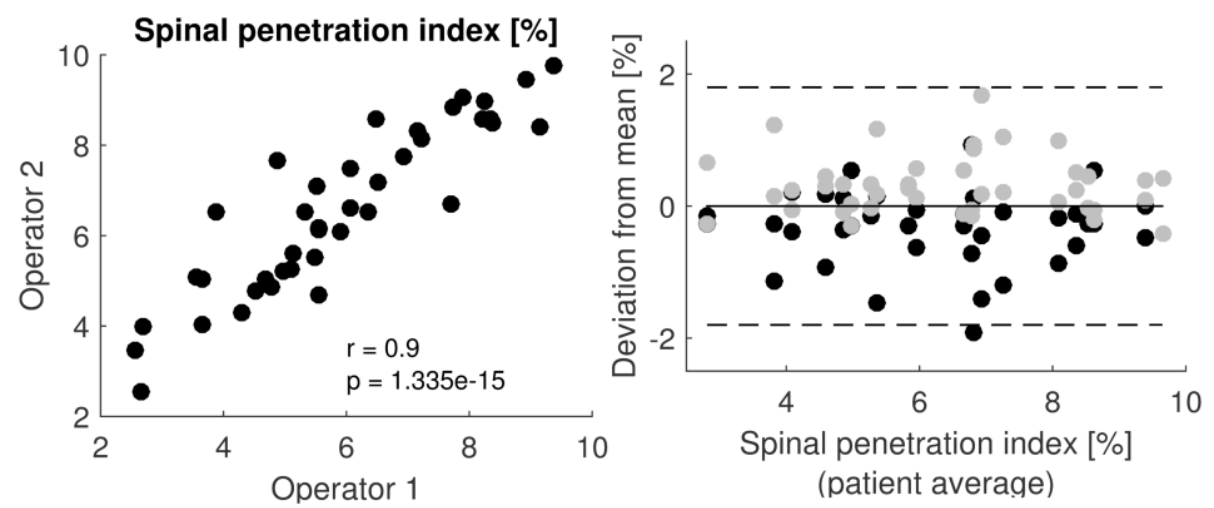

Figure 4: Spinal penetration index interoperator reproducibility: correlation between operators and Bland-Altmann plot. marked, which was time consuming. The evolution proposed by Aubert et al dramatically reduced the reconstruction time, but it was only validated on mild and moderate scoliosis.

The average rib cage volume was $4700 \mathrm{~cm}^{3} ;$ the interoperator reproducibility was $387.3 \mathrm{~cm} 3(8 \%)$ while the intraoperator repeatability was $233.4 \mathrm{~cm}^{3}$ (4\%). Comparing our results with Aubert et al[2] they reported an interoperator reproducibility of $294 \mathrm{~cm}^{3}$ and an intraoperator repeatability of $235 \mathrm{~cm}^{3}$. The difference between these results could be explained by the severity of scoliosis in our patients (mean major curve of $74^{\circ}$ vs $28^{\circ}$ in the compared 
study). In fact, in severe cases, costal deformations make the initial semiautomated reconstruction system less efficient, and the subsequent manual adjustment more complicated. The spinal penetration index reproducibility was $1.9^{\circ}$ while Aubert et al. reported $1.2^{\circ}$. The rib hump reproducibility was $3.5^{\circ}$ in our study $\left(5^{\circ}\right.$ reproducibility reported by Aubert et al.). This last result could be surprising; however, the smaller uncertainty in rib hump observed in severe scoliosis might be due to the highly asymmetrical rib cage, which allows an easy distinction of the left and right ribs at the patient's posterior aspect, thus reducing left-right inversion errors.

After analysing patient parameters with the greatest differences in reproducibility, we have not been able to identify factors significantly associated with poor reproducibility. In particular, an increase in scoliosis severity was not associated with a reproducibility decrease, as shown by the Bland-Altmann plots (Figures 3-5).

It is encouraging that low radiation techniques are being developed to estimate 3-D thoracic dimensions in spine deformity, but the validation of this technique in this report seem based solely on statistical analysis, not on pulmonary function testing or breathhold CT scans. The relationship between pulmonary function tests and rib cage deformity will be reported in a further study. We did observe good correlations between pulmonary function and rib cage geometrical parameters. However, before publishing these results, it was important to determine the uncertainty of the 3D reconstructions for such severe scoliotic spines.

We fully recognize some limitations in our study as for instance, it would be interesting to also assess the reproducibility of rib cage biplanar reconstruction after the surgery. However, it is unlikely that the surgical material affects the reproducibility of the rib cage. The reproducibility of the post-operative spine biplanar reconstructions have already been validated.[1] Biplanar X-rays can be used in young children. However, this requires them to remain standing still for fifteen seconds. The reconstructions of rib cage deformity due to severe abnormal development could be difficult. Moreover, bony structures are less visible in very young children because of incomplete calcification.

\section{CONCLUSION}

This study describes a reliable and reproducible three dimensional approach to evaluate rib cage parameters preoperatively in patients with AIS using biplanar X-rays, even for severe curves. The described parameters could have a clinical use in the scoliotic patient's follow-up. A full structural analysis of the spine and rib cage can be completed with only two low-dose biplanar radiographs. 


\section{References}

[1] Ilharreborde B, Steffen J.S, Nectoux E et Al Angle measurement reproducibility using EOS three-dimensional reconstructions in adolescent idiopathic scoliosis treated by posterior instrumentation', Spine, vol. 36, no. 20, pp. E1306-1313, Sep. 2011.

[2]Aubert B, Vergari C, Ilharreborde B et Al., '3D reconstruction of rib cage geometry from biplanar radiographs using a statistical parametric model approach', Comput. Methods Biomech. Biomed. Eng. Imaging Vis., 2014.

[3]Qiu Y, Sun G, Zhu F et Al 'Rib length discrepancy in patients with adolescent idiopathic scoliosis', Stud. Health Technol. Inform., vol. 158, pp. 63-66, 2010.

[4]Takahashi S, Suzuki S, Asazuma T, et Al 'Factors of thoracic cage deformity that affect pulmonary function in adolescent idiopathic thoracic scoliosis', Spine, vol. 32, no. 1, pp. 106-112, Jan. 2007.

[5]Dreimann M, Hoffmann M, Kossow K, et AL 'Scoliosis and chest cage deformity measures predicting impairments in pulmonary function: a cross-sectional study of 492 patients with scoliosis to improve the early identification of patients at risk', Spine, vol. 39, no. 24, pp. 2024-2033, Nov. 2014.

[6]Yazici M, Acaroglu E. R., Alanay A, et Al 'Measurement of vertebral rotation in standing versus supine position in adolescent idiopathic scoliosis', J. Pediatr. Orthop., vol. 21, no. 2, pp. 252-256, Apr. 2001.

[7]Torell G, Nachemson A, Haderspeck-Grib K, et Al 'Standing and supine Cobb measures in girls with idiopathic scoliosis', Spine, vol. 10, no. 5, pp. 425-427, Jun. 1985.

[8]Kalifa G, Charpak G, Maccia C, et Al 'Evaluation of a new low-dose digital xray device: first dosimetric and clinical results in children', Pediatr. Radiol., vol. 28, no. 7, pp. 557-561, Jul. 1998.

[9]Dubousset J, Charpak G, Skalli W et Al '[EOS stereo-radiography system: whole-body simultaneous anteroposterior and lateral radiographs with very low radiation dose]', Rev. Chir. Orthopédique Réparatrice Appar. Mot., vol. 93, no. 6 Suppl, pp. 141-143, Oct. 2007.

[10] G. Charpak, '[Prospects for the use in medicine of new detectors of ionizing radiation]', Bull. Académie Natl. Médecine, vol. 180, no. 1, pp. 161-168-169, Jan. 1996.

[11] Dubousset J, Charpak G, Dorion I, et Al '[A new 2D and 3D imaging approach to musculoskeletal physiology and pathology with low-dose radiation and the standing position: the EOS system]', Bull. Académie Natl. Médecine, vol. 189, no. 2, pp. 287-297-300, Feb. 2005.

[12] Humbert L, De Guise J.A, Aubert B, et Al'3D reconstruction of the spine from biplanar X-rays using parametric models based on transversal and longitudinal inferences', Med. Eng. Phys., vol. 31, no. 6, pp. 681-687, Jul. 2009.

[13] Erkula G, Sponseller P. D, Kiter A.E, 'Rib deformity in scoliosis', Eur. Spine 
J. Off. Publ. Eur. Spine Soc. Eur. Spinal Deform. Soc. Eur. Sect. Cerv. Spine Res. Soc., vol. 12, no. 3, pp. 281-287, Jun. 2003.

[14] Courvoisier A, Ilharreborde B, Constantinou B, et Al 'Evaluation of a ThreeDimensional Reconstruction Method of the Rib Cage of Mild Scoliotic Patients', Spine Deform., vol. 1, no. 5, pp. 321-327, Sep. 2013.

[15] Ilharreborde B, Dubousset J, Le Huec J.-C, 'Use of EOS imaging for the assessment of scoliosis deformities: application to postoperative 3D quantitative analysis of the trunk', Eur. Spine J. Off. Publ. Eur. Spine Soc. Eur. Spinal Deform. Soc. Eur. Sect. Cerv. Spine Res. Soc., vol. 23 Suppl 4, pp. S397-405, Jul. 2014.

[16] Hoffman D. A., Lonstein J. E, Morin M. M, et Al 'Breast cancer in women with scoliosis exposed to multiple diagnostic x rays', J. Natl. Cancer Inst., vol. 81, no. 17, pp. 1307-1312, Sep. 1989.

[17] Mitton D, Landry C., Véron S, et Al '3D reconstruction method from biplanar radiography using non-stereocorresponding points and elastic deformable meshes', Med. Biol. Eng. Comput., vol. 38, no. 2, pp. 133-139, Mar. 2000.

[18] Mitton D, Zhao K, Bertrand S, et Al '3D reconstruction of the ribs from lateral and frontal X-rays in comparison to 3D CT-scan reconstruction', J. Biomech., vol. 41, no. 3, pp. 706-710, 2008.

[19] Pomero V, Mitton D, Laporte S, et Al 'Fast accurate stereoradiographic 3Dreconstruction of the spine using a combined geometric and statistic model', Clin. Biomech. Bristol Avon, vol. 19, no. 3, pp. 240-247, Mar. 2004.

[20] Grenier S, Parent S, Cheriet F, 'Personalized 3D reconstruction of the rib cage for clinical assessment of trunk deformities', Med. Eng. Phys., vol. 35, no. 11, pp. 1651-1658, Nov. 2013.

[21] Jolivet E, Sandoz B, Laporte S, et Al 'Fast 3D reconstruction of the rib cage from biplanar radiographs', Med. Biol. Eng. Comput., vol. 48, no. 8, pp. 821-828, Aug. 2010.

[22] Sabourin M, Jolivet E, Miladi L, et Al 'Three-dimensional stereoradiographic modeling of rib cage before and after spinal growing rod procedures in early-onset scoliosis', Clin. Biomech. Bristol Avon, vol. 25, no. 4, pp. 284-291, May 2010. 